\title{
A case of hypervascular tumors in the liver and pancreas: synchronous hepatocellular carcinoma and pancreatic metastasis from renal cell carcinoma 36 years after nephrectomy
}

Hajime Nakamura ${ }^{1}$, Shingo Tanaka ${ }^{1}$, Koji Miyanishi ${ }^{1}$, Yutaka Kawano ${ }^{2}$, Takahiro Osuga ${ }^{1}$, Kazuma Ishikawa ${ }^{1}$, Makoto Yoshida ${ }^{1}$, Hiroyuki Ohnuma ${ }^{1}$, Kazuyuki Murase ${ }^{1}$, Kohichi Takada $^{1}$, Hiroshi Yamaguchi ${ }^{1}$, Minoru Nagayama ${ }^{1}$, Yasutoshi Kimura ${ }^{1}$, Ichiro Takemasa ${ }^{1}$, and Junji Kato ${ }^{1}$

${ }^{1}$ Sapporo Medical University

${ }^{2}$ Health Science University of Hokkaido

September 21, 2020

\begin{abstract}
It is sometimes difficult to distinguish between multiple cancers and metastases using only diagnostic imaging, particularly when multiple hypervascular tumors are found in multiple organs. In such cases, preoperative histological evaluation may be essential for determining the management of tumors.
\end{abstract}

\section{Hosted file}

manuscript_CCR.doc available at https://authorea.com/users/360542/articles/482191-a-case-ofhypervascular-tumors-in-the-liver-and-pancreas-synchronous-hepatocellular-carcinoma-andpancreatic-metastasis-from-renal-cell-carcinoma-36-years-after-nephrectomy

Nakamura, et al. Figure.1

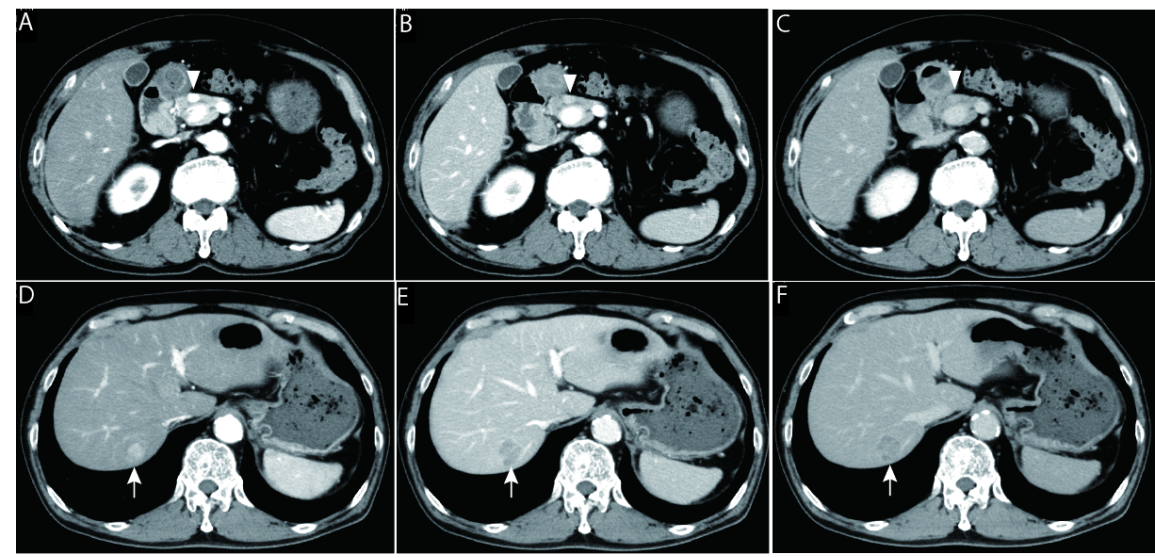


Nakamura, et al. Figure.2
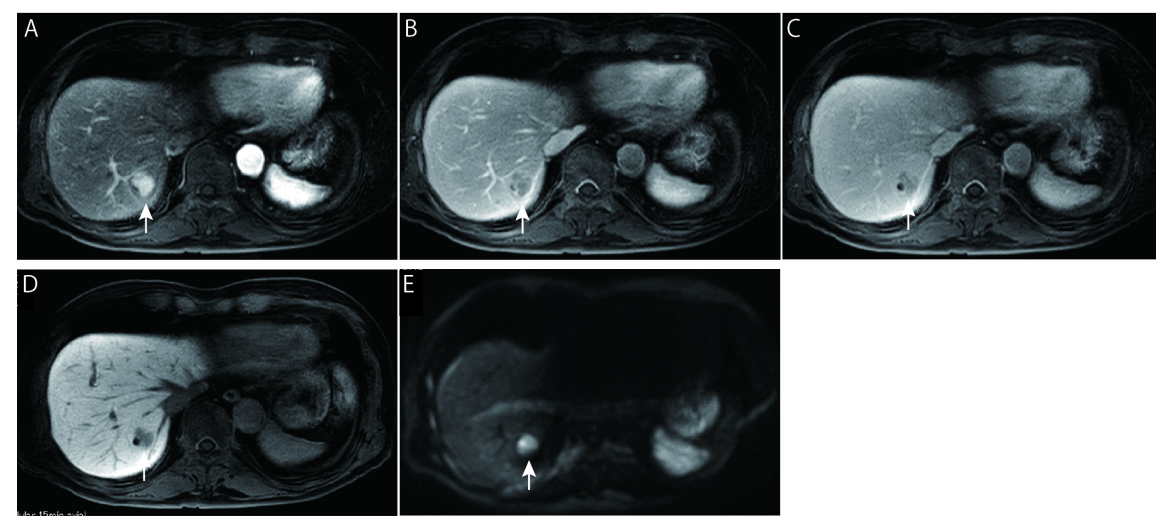

Nakamura, et al. Figure.3
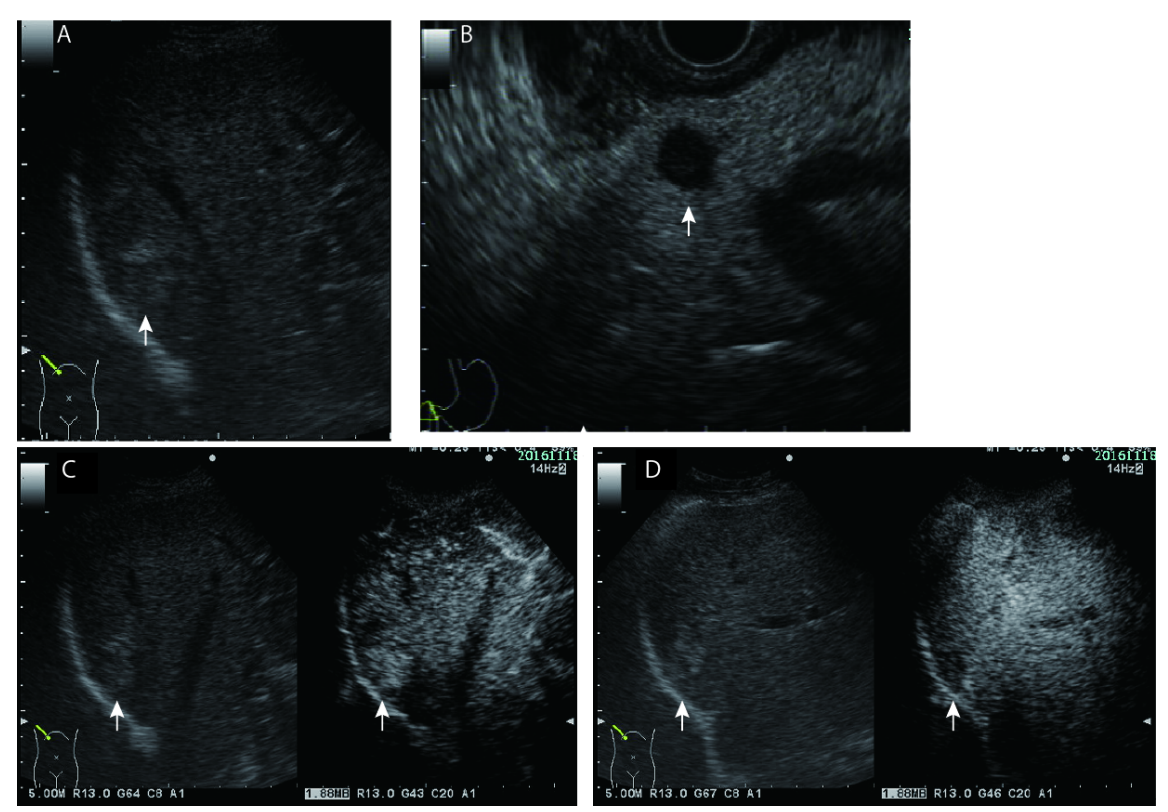

Nakamura, et al. Figure.4

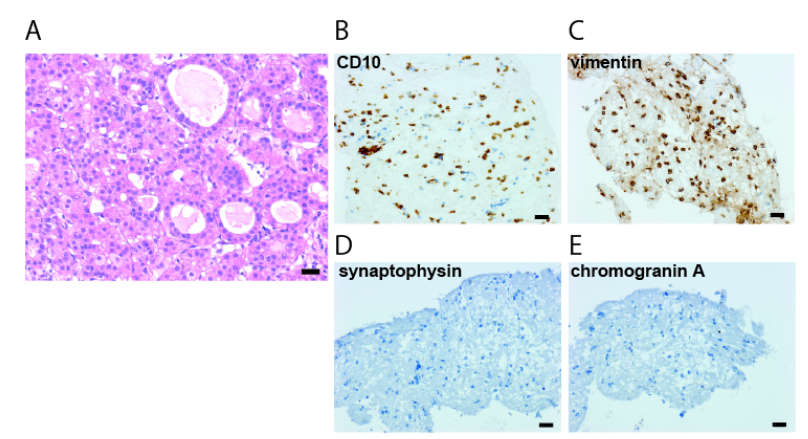

$\mathrm{F}$

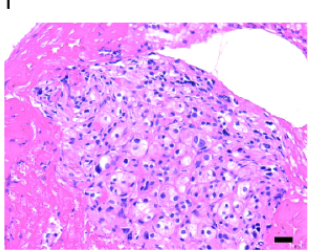




\section{Hosted file}

Table1.docx available at https://authorea.com/users/360542/articles/482191-a-case-ofhypervascular-tumors-in-the-liver-and-pancreas-synchronous-hepatocellular-carcinomaand-pancreatic-metastasis-from-renal-cell-carcinoma-36-years-after-nephrectomy 